\title{
Properties of PHA bi-, ter-, and quarter-polymers containing 4-hydroxybutyrate monomer units
}

\author{
Natalia Zhila, ${ }^{\mathrm{a}, \mathrm{b}}{ }^{*}$, Ekaterina Shishatskaya ${ }^{\mathrm{a}, \mathrm{b}}$ \\ ${ }^{a}$ Siberian Federal University, 79 Svobodnyi Avenue, Krasnoyarsk, 660041, Russian Federation \\ ${ }^{\mathrm{b}}$ Institute of Biophysics SB RAS, Federal Research Center "Krasnoyarsk Science Center SB \\ RAS", Akademgorodok, Krasnoyarsk, 660036, Russian Federation
}

*Corresponding author. Tel.: +7 391 2494428; fax: +7 3912433400

E-mail address: nzhila@mail.ru (Natalia Zhila)

\begin{abstract}
The present study investigates physicochemical, mechanical, and biological properties of polyhydroxyalkanoate (PHA) copolymers containing 4-hydroxybutyrate (4HB) synthesized in Cupriavidus eutrophus B10646 culture. In poly(3-hydroxybutyrate/4-hydroxybutyrate) $[\mathrm{P}(3 \mathrm{HB} / 4 \mathrm{HB})]$ bipolymers, 4HB varied between 10.4 and $75.0 \mathrm{~mol} \%$; in poly $(3-$ hydroxybutyrate/3-hydroxyvalerate/4-hydroxybutyrate) terpolymers, 4HB constituted 28.7-55.6 mol.\%; and in poly(3-hydroxybutyrate/3-hydroxyvalerate/4-hydroxybutyrate/3hydroxyhexanoate) quaterpolymers, $4 \mathrm{HB}$ varied between 9.3 and $13.3 \mathrm{~mol} \%$. The degree of crystallinity of $\mathrm{P}(3 \mathrm{HB} / 4 \mathrm{HB})$ copolymers decreased consistently with an increase in $4 \mathrm{HB}$ content, reaching 38\%. The incorporation of 3-hydroxyvalerate and 3-hydroxyhexanoate into copolymers enhanced that effect. The effect of $4 \mathrm{HB}$ monomer units on temperature properties of copolymers was exhibited as lowering of the melting temperature and crystallization temperature, which improved the processing-related properties of the copolymers. All copolymers containing 4HB showed enhanced elongation at break compared to poly(3-hydroxybutyrate). Polymer films prepared from PHAs with different chemical composition had similar microstructure and porosity and had no toxic effect on mouse fibroblast NIH 3T3 cells, proving their high biocompatibility.
\end{abstract}

Keywords: polyhydroxyalkanoates, 4-hydroxybutyrate monomer units, physicochemical and mechanical properties 


\section{Introduction}

Development of new materials is among the priorities for critical technologies at the global level. Special emphasis is placed on developing and investigating materials for biomedical applications, which are intended to come into contact with the internal environment of living organisms and which are necessary to enhance the efficacy of reconstructive processes in damaged tissues and organs [1]. The diversity of polymers that have widely varying properties, the possibility of constructing hybrids with different substances, and the availability of numerous techniques for processing them provide the basis for producing an extensive range of novel materials with new valuable properties. Polymers of hydroxy-derived carbonic acids of microbial origin, polyhydroxyalkanoates (PHAs), are a useful product of biotechnology. PHAs are biodegradable, biocompatible, and thermoplastic polymers with various chemical compositions, which do not undergo abiotic hydrolysis in aqueous medium and whose properties (molecular weight, crystallinity, mechanical strength, and biodegradability) vary considerably depending on their monomer composition and proportions of monomer units [2-4].

Of the various PHAs, poly(3-hydroxybutyrate/4-hydroxybutyrate) copolymers $[\mathrm{P}(3 \mathrm{HB} / 4 \mathrm{HB})]$ deserve special attention. They are elastomeric materials with enhanced elongation and tensile strength. The first products approved by the FDA for clinical uses were $\mathrm{P}(3 \mathrm{HB} / 4 \mathrm{HB})-$ based devices designed by Tepha (U.S.) (http://www.tepha.com/pipelinedrugdelivery.htm). $\mathrm{P}(3 \mathrm{HB} / 4 \mathrm{HB})$ copolymers can be synthesized by both wild-type and genetically modified strains under specialized cultivation conditions, in the culture medium supplemented with such precursors of 4-hydroxybutyrate (4HB) monomers as $\gamma$-hydroxybutyric acid, $\gamma$-butyrolactone, 1,4-butanediol, etc. These substances, however, inhibit the growth of microorganisms, decreasing cell biomass production, total copolymer yields, and the 4HB fraction of the copolymer. Therefore, there are only relatively limited data available regarding the properties and potential for wide-scale application of these copolymers. Published studies mainly report results of synthesis and investigation of $\mathrm{P}(3 \mathrm{HB} / 4 \mathrm{HB})$ copolymers comprising two 
1 components, with different 4HB fractions [5-9]. A number of papers addressed the effect of 4HB

2 monomer concentration on the temperature and molecular-weight characteristics of $\mathrm{P}(3 \mathrm{HB} / 4 \mathrm{HB})$

3 copolymers and their mechanical properties [3, 10-13]. There are few published data on PHA

4 terpolymers containing 4HB. Several studies described poly(3-hydroxybutyrate/3-

5 hydroxyvalerate/4-hydroxybutyrate) $[(\mathrm{P}(3 \mathrm{HB} / 3 \mathrm{HV} / 4 \mathrm{HB})]$ copolymers with different monomer

6 fractions and their temperature and molecular-weight properties [14-17]. Until recently, no data

7 on the properties of PHA quaterpolymers containing $4 \mathrm{HB}$ monomer units have been found in the

8 available literature.

The authors of this study have assembled a collection of bacterial strains capable of 10 synthesizing high yields of PHAs on various substrates and studied PHA synthesis under 11 different conditions of carbon nutrition. Based on this, they managed to synthesize not only poly12 3-hydroxybutyrate but also copolymers of various compositions: 3HB/diethylene glycol $13[\mathrm{P}(3 \mathrm{HB} / \mathrm{DEG})]$ copolymer [18], bipolymers of $3 \mathrm{HB}$ with 3-hydroxyvalerate (3HV) and 3hydroxy-4-methylvalerate [19], and a series of PHA ter- and quarterpolymers composed of 15 various short- and medium-chain-length monomers in different proportions, including ones 16 containing various concentrations of 4-hydroxybutyrate [20-23].

The purpose of this study was to investigate and compare physical, mechanical, and biological properties of PHA bi-, ter-, and quarter-polymers containing various concentrations of 4HB.

\section{Experimental}

\subsection{Materials}

Samples of PHAs of different composition were synthesized by using Cupriavidus eutrophus B10646 wild strain, at the Institute of Biophysics SB RAS. Cells were batch-cultured under strictly aseptic conditions, following the previously developed technology [20-21]. PHAs of different compositions were synthesized using precursor substrates such as valeric acid, 26 hexanoic acid and $\gamma$-butyrolactone. Polymer was extracted from cells with chloroform, and the 
1 extracts were precipitated using hexane. The extracted polymers were re-dissolved and

2 precipitated again 3-4 times to prepare homogeneous specimens.

\subsection{Analysis of PHA structure}

${ }^{1} \mathrm{H}$ NMR spectra of PHA were recorded at room temperature in $\mathrm{CDCl}_{3}$ on a BRUKER AVANCE III 600 spectrometer (Germany) operating at $600.13 \mathrm{MHz}$.

\subsection{Analysis of physicochemical properties of PHAs}

Molecular weight and molecular-weight distribution of PHAs were examined with a gel permeation chromatograph (“Agilent Technologies” 1260 Infinity, U.S.) with a refractive index detector, using an Agilent PLgel Mixed-C column.

Thermal analysis of PHA specimens was performed using a DSC-1 differential scanning calorimeter (METTLER TOLEDO, Switzerland). The specimens were heated at a rate of 5 ${ }^{\circ} \mathrm{C} /$ min to $200{ }^{\circ} \mathrm{C}$, then cooled to $-20{ }^{\circ} \mathrm{C}$, held for 20 minutes and re-heated to $320{ }^{\circ} \mathrm{C}$. Glass transition temperature $(T g)$, crystallization temperature $(T c)$, melting point (Tmelt) and thermal degradation temperature (Tdegr) were determined from peaks in thermograms using the "StarE" software.

X-Ray structure analysis and determination of crystallinity of copolymers were performed employing a D8 ADVANCE X-Ray powder diffractometer equipped with a VANTEC fast linear detector (Bruker, AXS, Germany). Calculations were done by using the Eva program of the diffractometer software.

\subsection{Analysis of PHA surface microstructure}

Films of PHAs were prepared by casting chloroform solution $(2 \% \mathrm{w} / \mathrm{v})$ on degreased glass and subsequent drying at room temperature for 2-3 days in a dust-free box. The film discs were $100 \mathrm{~mm}$ in diameter and $0.04 \mathrm{~mm}$ thick.

The microstructure of the surface of PHA films was analyzed using scanning electron microscopy (S 5500, Hitachi, Japan).

The roughness of film surface was determined using atomic-force microscopy (AFM) in 
1 semicontact mode (Smart SPMTM, AIST-NT, Zelenograd, Russia).

2 Surface properties of the polymer films were examined using a DSA-25E drop shape 3 analyzer (Krüss, Germany) and software DSA-4 for Windows.

\subsection{Analysis of physical/mechanical properties of PHAs}

Physical and mechanical properties of the films prepared from PHAs with different compositions were investigated using an Instron 5565 electromechanical tensile testing machine (U.K.). Dumbbell-shaped samples $50 \mathrm{~mm}$ long, $6.1 \mathrm{~mm}$ wide, and 25-30 $\mu \mathrm{m}$ thick were prepared for studying physical and mechanical properties of the films. The speed of the crosshead was 3 $\mathrm{mm} / \mathrm{min}$ at ambient temperature. Young's modulus (E, MPa), tensile strength $(\sigma, \mathrm{MPa})$ and elongation at break $(\varepsilon, \%)$ were automatically calculated by the Instron software (Bluehill 2, Elancourt, France).

\subsection{Cell attachment assay}

Films were cut into disks $10 \mathrm{~mm}$ in diameter, using a mold cutter, and sterilized with $\mathrm{H}_{2} \mathrm{O}_{2}$ plasma in the Sterrad NX system (Johnson \& Johnson, USA) for $45 \mathrm{~min}$. The ability of ultrafine PHA films to facilitate cell attachment was studied using NIH 3T3 mouse fibroblast cells. Morphology of cells attached to film surface was determined using DAPI and FITC fluorescent dyes (DNA and cytoplasm markers).

Characterization was done using procedures similar to previously described ones [20-21].

\section{Results and Discussion}

Strain Cupriavidus eutrophus B10646 cultivated under specialized conditions of carbon nutrition synthesized polymers with different proportions of $4 \mathrm{HB}$ monomer units: $\mathrm{P}(3 \mathrm{HB} / 4 \mathrm{HB})$ bipolymers with $4 \mathrm{HB} 10.4-75.0$ mol.\% (3HB constituting the other fraction); $\mathrm{P}(3 \mathrm{HB} / 3 \mathrm{HV} / 4 \mathrm{HB})$ terpolymers with 4HB 28.7-55.6 mol.\% (with 3HV 10.1 -20.5 and 3HB 27.4-51.5 mol.\%), and poly(3-hydroxybutyrate/3-hydroxyvalerate/4-hydroxybutyrate/3-hydroxyhexanoate)

$[(\mathrm{P}(3 \mathrm{HB} / 3 \mathrm{HV} / 4 \mathrm{HB} / 3 \mathrm{HHx})]$ quaterpolymers with 4HB 9.3 - 13.3 mol.\% (with $3 \mathrm{HV} 6.4$-20.9, 3HHx 1.4-2.5, and 3HB 63.9-82.9 mol.\%) (Table 1). 
The chemical composition of monomers in the PHAs was identified using NMR

2 spectrometry. Figure 1 shows examples of NMR spectra characterizing the chemical

3 composition of PHA bi-, ter-, and quaterpolymers.

4

\subsection{Physicochemical properties of PHA copolymers with different compositions}

The proportions of monomers influenced physicochemical properties of PHAs, including their degrees of crystallinity and molecular-weight and temperature characteristics (Table 1).

\subsubsection{Degree of crystallinity}

Degree of crystallinity $\left(\mathrm{C}_{\mathrm{x}}\right)$, which is determined by the ratio of amorphous to crystalline regions, is a fundamental property of polymeric materials, influencing their fine structure, thermomechanical properties, techniques employed to process polymers into products, and properties of these products. PHAs are semi-crystalline materials, and PHA crystallization is determined by the structure of the carbon chain. PHA crystallization occurs at different temperatures $\left(T_{c}\right)$, and some portions of the bulk are not crystallized. Thus, these polymers comprise two phases (crystalline and amorphous ones), and their ratio is largely determined by the composition and proportions of monomers. However, the available information on the degrees of crystallinity of PHAs with different concentrations of $4 \mathrm{HB}$ is too scarce to definitively determine the effect of this monomer on $\mathrm{C}_{\mathrm{x}}$.

Incorporation of $4 \mathrm{HB}$ monomer units into the carbon chain of 3-hydroxybutyrate (3HB) considerably changed the ratio of amorphous to crystalline regions in all copolymers, decreasing $\mathrm{C}_{\mathrm{x}}$ to different extents (Table 1$)$. The $\mathrm{P}(3 \mathrm{HB} / 4 \mathrm{HB})$ bipolymers containing between 10.4 and 75.0 mol. $\%$ 4HB showed the degree of crystallinity below 55\%, and this value consistently decreased as the proportion of $4 \mathrm{HB}$ increased. The copolymers with 4HB below 50\% (10.4, 15.0 and 29.3 mol.\%) had the degree of crystallinity about 50\% (53, 50 and 46\%); in the copolymer consisting on nearly equal molar fractions of 4HB and 3HB (Sample 4, Table 1), the amorphous region was larger than the crystalline one $\left(\mathrm{C}_{\mathrm{x}}\right.$ was $\left.40 \%\right)$. Finally, in the copolymer with $4 \mathrm{HB}$ constituting 75 mol. $\%$, the degree of crystallinity dropped to $30 \%$. Mitomo et al. investigated $\mathrm{P}(3 \mathrm{HB} / 4 \mathrm{HB})$ 
1 copolymers with $4 \mathrm{HB}$ between 10 and 94 mol.\% and reported a decrease in $\mathrm{C}_{\mathrm{x}}$ to $18-50 \%$

2 relative to $\mathrm{P}(3 \mathrm{HB})(72 \%)$, but the authors did not find any clear relationship between this

3 decrease and the percentage of 4HB [24]. Other studies also presented contradictory data on the

4 effects of the molar fraction of $4 \mathrm{HB}$ in $\mathrm{P}(3 \mathrm{HB} / 4 \mathrm{HB})$ on $\mathrm{C}_{\mathrm{x}}$. For instance, in a study by

5 Ramachandran and Amirul, $\mathrm{C}_{\mathrm{x}}$ reached $41 \%$ in the sample with a very low $4 \mathrm{HB}$ fraction (3

6 mol.\%) and 2-10\% in copolymers with higher proportions of 4HB (15-40 mol.\%) [13]. Iqbal and

7 Amirul investigated a wider range of $\mathrm{P}(3 \mathrm{HB} / 4 \mathrm{HB})$ copolymers, which contained $4 \mathrm{HB}$ between

$8 \quad 10$ and 65 mol.\%; the $\mathrm{C}_{\mathrm{x}}$ of the copolymers with $4 \mathrm{HB}$ increasing from 10 to $30 \mathrm{~mol} . \%$ dropped

9 dramatically (from 31.6 to $12.9 \%$ ) while the samples with higher $4 \mathrm{HB}$ percentage were

10 amorphized, and crystalline regions were undetectable [12].

11 A more noticeable decrease in the degree of crystallinity was observed in $12 \mathrm{P}(3 \mathrm{HB} / 3 \mathrm{HV} / 4 \mathrm{HB})$ terpolymers (Samples 6-8, Table 1). Even in the copolymers that did not contain very high proportions of 4HB (28.7 and 38.4 mol.\%) and 3HV (10.1-20.5 mol.\%), which also decreased $\mathrm{C}_{\mathrm{x}}$, the degree of crystallinity was below 50\% (35-33\%). Thus, $4 \mathrm{HB}$ and $3 \mathrm{HV}$ together had a stronger effect on the ratio of amorphous to crystalline regions in the copolymer 16 than either of these monomers alone. The $\mathrm{C}_{\mathrm{x}}$ of the terpolymer containing 4HB 55.6 mol.\% (with $3 \mathrm{HB}$ and $3 \mathrm{HV} 27.4$ and 17.0 mol.\%, respectively) was $26 \%$.

In the $\mathrm{P}(3 \mathrm{HB} / 3 \mathrm{HV} / 4 \mathrm{HB} / 3 \mathrm{HHx})$ quaterpolymers, the proportions of $4 \mathrm{HB}$ were not very high $(9.3,10.1$, and $13.3 \mathrm{~mol} \%$ ); the major component was 3HB (63.9 - 82.9 mol.\%), with the other three monomers (4HB, $3 \mathrm{HV}$, and $3 \mathrm{HHx}$ ) totaling between 17.1 and $36.1 \mathrm{~mol} \%$. The $\mathrm{C}_{\mathrm{x}}$ of these copolymers was below $50 \%$. A search of the literature did not reveal any data on the $\mathrm{C}_{\mathrm{x}}$ of the PHA terpolymers and quaterpolymers of the same or similar composition. There are data, however, showing that incorporation of other monomer units $(3 \mathrm{HV}, 4 \mathrm{HB}$ or $3 \mathrm{HHx})$ into the carbon chain of $3 \mathrm{HB}$ leads to formation of different types of the crystalline lattice, depending on the contents of the incorporated monomers [6, 25-27]. Our results suggest that the degree of crystallinity of PHAs can be decreased by synthesizing $\mathrm{P}(3 \mathrm{HB} / 4 \mathrm{HB})$ bipolymers, and that the 
1 degree of crystallinity decreases more noticeably with an increase in the 4HB content. The $C_{x}$

2 can also be decreased by incorporating a greater number of monomer units other than $3 \mathrm{HB}$, i.e.

3 by synthesizing terpolymers and quaterpolymers containing not only $4 \mathrm{HB}$ but also $3 \mathrm{HV}$ and

$43 \mathrm{HHx}$, which contribute to achieving a balance between the amorphous and crystalline regions in

5 the polymer.

\subsubsection{Molecular weight properties}

PHA molecular weight is a highly variable parameter, which is determined by a number of factors such as the type of the PHA-producing microorganism, carbon source, duration of cultivation, and technique of polymer extraction. For instance, molecular weight of $\mathrm{P}(3 \mathrm{HB})$ may vary between 200 and $3000 \mathrm{kDa}$ [24, 28-29]. Analysis of $\mathrm{P}(3 \mathrm{HB} / 4 \mathrm{HB})$ bipolymers did not reveal any clear relationship between the chemical composition and $4 \mathrm{HB}$ content, on the one hand, and weight average molecular weight $\left(M_{w}\right)$, on the other. The $M_{w}$ values of different copolymers varied between 570 and $830 \mathrm{kDa}$, with no correlation with the increasing 4HB fraction, and these values were close to those of $\mathrm{P}(3 \mathrm{HB})$. However, number average molecular weight $\left(M_{n}\right)$ was 1.5 2.0 times lower than the $M_{n}$ of $\mathrm{P}(3 \mathrm{HB})$. That also influenced the value of polydispersity, which increased to 3.0-4.7 as $4 \mathrm{HB}$ content was increased, suggesting higher non-uniformity of the polymer - the presence of a greater number of fragments with different degrees of polymerization. A number of studies [12-13, 24, 29-30] addressed molecular weight properties of $\mathrm{P}(3 \mathrm{HB} / 4 \mathrm{HB})$ bipolymers with different percentages of 4HB (5 to $94 \mathrm{~mol} . \%)$ but did not reveal any direct relationship between $4 \mathrm{HB}$ content and weight average molecular weight $\left(M_{w}\right)$ of the polymer. In different studies, the $M_{w}$ varied between 100-200 and 400-600 kDa, tending to decrease somewhat in the polymers with $4 \mathrm{HB}$ higher than $40-50$ mol.\%. The number average molecular weight $\left(M_{n}\right)$ reported by different authors for the copolymers containing comparable proportions of 4HB (23-24 mol.\%) varied widely, between 104 and $590 \mathrm{kDa}$ [7, 11]. That also affected polydispersity of $\mathrm{P}(3 \mathrm{HB} / 4 \mathrm{HB})$, which varied between $0.6-1.0-2.0$ [30] and 2.5-3.5 [1213]. 
No direct relationship was found between the chemical composition and 4HB content, on

2 the one hand, and $M_{w}$ and $M_{n}$, on the other, in terpolymers either (Table 1). The $M_{w}$ of different

3 samples ranged between 490 and $580 \mathrm{kDa}$ and the $M_{n}$ between 160 and $180 \mathrm{kDa}$. Polydispersity,

4 which shows the proportions of fragments with different degrees of polymerization in the

5 polymer, ranged between 2.9 and 3.4 and was generally higher than $\mathrm{P}(3 \mathrm{HB})$ polydispersity

6 (Table 1). Terpolymers consisting of the same monomer units were investigated in a number of

7 studies [14-17, 31]. In those studies, 4HB content of the copolymers varied widely (between 10

8 and 94 mol.\%). The $M_{w}$ and $Đ$ values varied between 177 and $1100 \mathrm{kDa}$ and between 1.13 and

96.46 , respectively, and they were not related to monomer proportions and 4HB content.

Similar results were obtained in the study of quaterpolymers (Table 1). $M_{w}$ varied

11 between 580 and $790 \mathrm{kDa}$; increased polydispersity ranged between 4.5 and 5.3 in different samples. The highest values were measured in the sample with the lowest $3 \mathrm{HB}$ content and the highest total content of the three other monomers, including 4HB. Thus, 4HB content was generally found to affect $M_{n}$ and polydispersity.

\subsubsection{Temperature properties}

The melting temperature $\left(T_{\text {melt }}\right)$ of PHAs, including the $\mathrm{P}(3 \mathrm{HB})$ homopolymer, is about $100{ }^{\circ} \mathrm{C}$ lower than their temperature of onset of thermal degradation $\left(T_{\text {degr }}\right)$. This is an essential technological property, as it enables fabrication of polymer products from melts. Incorporation of 4HB monomer units into the $3 \mathrm{HB}$ chain produced different effects on temperature properties of PHA copolymers, depending on $4 \mathrm{HB}$ content and presence of other monomers $(3 \mathrm{HV}, 3 \mathrm{HHx})$ in the polymer.

All $\mathrm{P}(3 \mathrm{HB} / 4 \mathrm{HB})$ bipolymers showed melting temperatures that were somewhat lower than $T_{\text {melt }}$ of $\mathrm{P}(3 \mathrm{HB})\left(178{ }^{\circ} \mathrm{C}\right)$. The $T_{\text {melt }}$ values of the $\mathrm{P}(3 \mathrm{HB} / 4 \mathrm{HB})$ copolymers that contained 4HB between 10.4 and 75.0 mol.\% ranged between 150 and $162{ }^{\circ} \mathrm{C}$, and the copolymer containing $4 \mathrm{HB} 10.4 \mathrm{~mol} \%$ had the lowest $T_{\text {melt }}$. In contrast to $T_{\text {melt }}, T_{\text {degr }}$ values were similar in all bipolymers, irrespective of the $4 \mathrm{HB}$ content, ranging between 295 and $299{ }^{\circ} \mathrm{C}$, which was 
1 comparable with the $T_{\text {degr }}$ of $\mathrm{P}(3 \mathrm{HB})\left(295^{\circ} \mathrm{C}\right)$. Not all PHA types showed glass transition. The 2 glass transition temperature $\left(T_{g}\right)$ of $\mathrm{P}(3 \mathrm{HB} / 4 \mathrm{HB})$ copolymers containing $4 \mathrm{HB} 10.4$ and 15.0 3 mol.\% was $\left(3.4{ }^{\circ} \mathrm{C}\right)$ and $\left(-2.6^{\circ} \mathrm{C}\right)$, respectively; the thermograms of the copolymers with higher $44 \mathrm{HB}$ contents $(29.3-75.0 \mathrm{~mol} \%)$ taken under measurement conditions did not show any glass 5 transition regions (Samples 3-5, Table 1). The highest crystallization temperature was exhibited 6 by pure $\mathrm{P}(3 \mathrm{HB})$, and of the copolymers, Samples 3 and 4 had the highest $T_{c}$ (Table 1 ). The $T_{c}$ of 7 the copolymers with relatively low $4 \mathrm{HB}$ contents $(10.4-15.0 \mathrm{~mol} . \%)$ was about $57-66{ }^{\circ} \mathrm{C}$; as the $84 \mathrm{HB}$ content increased, the $T_{c}$ rose to $88-97^{\circ} \mathrm{C}$. The lower crystallization temperature of the 9 copolymers compared to $\mathrm{P}(3 \mathrm{HB})$ suggests that the copolymers remain highly ductile for longer 10 time periods and, thus, are more readily processable. There are literature data both confirming and 11 contradicting our results. The temperature properties of $\mathrm{P}(3 \mathrm{HB} / 4 \mathrm{HB})$ have been examined by very many researchers, but the published data vary greatly, even for copolymers containing similar proportions of monomer units. For instance, in a study by Mitomo et al., the melting temperature $\left(T_{\text {melt }}\right)$ of $\mathrm{P}(3 \mathrm{HB} / 4 \mathrm{HB})$ copolymers containing $4 \mathrm{HB}$ between 19 and 94 mol.\% consistently decreased with the increase in the 4HB fraction [24]. The $T_{\text {melt }}$ of the copolymer with the lowest 4HB fraction was $158{ }^{\circ} \mathrm{C}$, dropping dramatically, to 44 and $54{ }^{\circ} \mathrm{C}$, when the $4 \mathrm{HB}$ content was increased to 74 and $94 \mathrm{~mol} \%$, respectively, and the $T_{g}$ decreased by one order of magnitude, from -4 to $-40^{\circ} \mathrm{C}$. A similar $T_{m e l t}$ decrease, to $40-54{ }^{\circ} \mathrm{C}$, was observed when the $4 \mathrm{HB}$ content of the copolymer was increased to 75-100 mol.\% [7, 14]. Doi et al., however, found that the $T_{m e l t}$ of the copolymer with the high $4 \mathrm{HB}$ fraction $\left(84 \mathrm{~mol} \%\right.$ ) was at least $130^{\circ} \mathrm{C}[5] . \mathrm{A}$ number of authors showed that $T_{m e l t}$ and $T_{g}$ varied depending on 4HB content: as 4HB content was increased from 10-40 to 50-90 mol.\%, both parameters dropped from $150-160$ and $-2-10{ }^{\circ} \mathrm{C}$ to $40-50$ and -

$23 \quad 35-48{ }^{\circ} \mathrm{C}$, respectively $[6,29]$. The authors of another study [13], however, did not reveal any effect of the increase in the $4 \mathrm{HB}$ content from 3 to $40 \mathrm{~mol} \%$ on the $T_{\text {melt }}$ of the copolymers, which was about $145-155{ }^{\circ} \mathrm{C}$ for all samples. Iqbal and Amirul reported a somewhat lower 
1 melting temperature $\left(121-132^{\circ} \mathrm{C}\right)$ for the $\mathrm{P}(3 \mathrm{HB} / 4 \mathrm{HB})$ copolymers with comparable $4 \mathrm{HB}$

2 contents (20 to $30 \mathrm{~mol} . \%)$ [12].

3 The values of $T_{\text {melt }}$ obtained for terpolymers and quaterpolymers were $9-17^{\circ} \mathrm{C}$ lower than

4 the $T_{\text {melt }}$ of $\mathrm{P}(3 \mathrm{HB})$, decreasing as the $4 \mathrm{HB}$ content increased. At the same time, the $T_{\text {degr }}$ were 5 comparable with the corresponding parameter of $\mathrm{P}(3 \mathrm{HB})$. Determination of the $T_{g}$ and $T_{c}$ in the 6 study of terpolymers and quaterpolymers gave the following results. Two terpolymers with 7 different proportions of monomer units had the same $T_{g},-5^{\circ} \mathrm{C}$. However, the copolymer with the 8 highest $4 \mathrm{HB}$ content, $55.6 \mathrm{~mol} \%$, showed no peak characterizing glass transition (Sample 8,

9 Table 1). For the quaterpolymers with $3 \mathrm{HB}$ as the major component $(63.9,74.7$, and 82.9 mol.\%) 10 and the total content of the other monomer units $(3 \mathrm{HV}, 4 \mathrm{HB}$, and $3 \mathrm{HHx})$ varied but kept below $1150 \%\left(36.1,25.3\right.$, and $17.1 \mathrm{~mol} . \%$, respectively), the $T_{g}$ was $-0.7,-3.1$, and $-4.4{ }^{\circ} \mathrm{C}$ (Samples $9-11$, 12 Table 1$)$. The $T_{c}$ of quaterpolymers $\left(51-70{ }^{\circ} \mathrm{C}\right)$ was generally higher than the $T_{c}$ of $\mathrm{P}(3 \mathrm{HB})$. The 13 literature search showed the following. Madden et al. investigated temperature properties of $3 \mathrm{HB} / 3 \mathrm{HV} / 4 \mathrm{HB}$ with $3 \mathrm{HB}$ as the major component (74-93 mol.\%) and low contents of 4HB (5-13 mol.\%) and $3 \mathrm{HV}(2-10 \mathrm{~mol} . \%)$ and revealed a drop in the $T_{\text {melt }}$ from 160 to $100^{\circ} \mathrm{C}$ and energy of 16 crystallization from 70 to $49 \mathrm{~J} / \mathrm{g}$ [31]. It is important that the decrease in the $T_{\text {melt }}$ and the $T_{\operatorname{degr}}$ of the terpolymers and quaterpolymers studied did not significantly decrease the difference between these parameters. Thus, the PHA copolymers investigated in this study, whatever their composition and monomer proportions, retained one of the essential properties of PHAs thermoplasticity.

\subsection{Physical/mechanical properties of PHAs with different compositions}

Surface properties of polymer products are important for evaluating their potential performance characteristics. To investigate surface properties and mechanical properties of 4HBcontaining PHAs with different compositions, we prepared $25 \pm 0.3-\mu \mathrm{m}$ thick smooth transparent films. 


\subsubsection{Characterization of the surface properties}

Results of studying the microstructure of polymer film surface are shown in Figure 2 and Table 2. SEM images of the samples prepared from polymers with different chemical composition and differing in their physicochemical properties looked dissimilar; the surfaces of copolymer films, in contrast to the surface of $\mathrm{P}(3 \mathrm{HB})$-based ones, were developed (to different degrees), porous, and uneven. The surface of the $\mathrm{P}(3 \mathrm{HB})$ films was smoother and denser, with a few small pores, of diameter of no more than $0.5 \mu \mathrm{m}$. The surface structure of the films prepared from bipolymers was noticeably different from the surface structure of $\mathrm{P}(3 \mathrm{HB})$ film (Fig. 3f) in that it was rougher and had pores of diameter between 0.5 and $5 \mu \mathrm{m}$ and prominent circular structures (Fig. 3a, b). The surface of the films prepared from terpolymers and quaterpolymers was also rougher, with very many pores of different diameters (between 0.5 and $6 \mu \mathrm{m})$ (Fig. 3c, d, e).

A significant parameter, which indirectly characterizes biocompatibility and influences cell adhesion and viability, is hydrophilic/hydrophobic balance of the surface [32]. It is evaluated by measuring contact angles for water. These measurements provide the basis for determining such important parameters of the surface as cohesive forces, surface tension, and interfacial free energy. Morphological characteristics of films with different compositions influenced the values of contact angles for water and parameters determined from them: surface energy and polar component of surface free energy (Table 2).

Different contact angles for water were obtained for films prepared from $\mathrm{P}(3 \mathrm{HB} / 4 \mathrm{HB})$ bipolymers, 4HB-containing terpolymers, quaterpolymers, and $\mathrm{P}(3 \mathrm{HB}): 78.6-92.5^{\circ}, 81.7-96.6^{\circ}$, $88.9-99.7^{\circ}$, and $97.4^{\circ}$, respectively. The values of surface free energy were also different: 36.7 - $44.5 \mathrm{erg} / \mathrm{cm}^{2}, 20.7-39.3 \mathrm{erg} / \mathrm{cm}^{2}, 34.5-40.9 \mathrm{erg} / \mathrm{cm}^{2}$, and $30.4 \mathrm{erg} / \mathrm{cm}^{2}$, respectively. The values of the polar component of surface free energy increased in copolymers, in PHA bipolymers and terpolymers in particular, compared with $\mathrm{P}(3 \mathrm{HB})$, indirectly indicating a more hydrophilic surface. 
Another important property necessary to characterize the surface is roughness, which

2 determines adhesion. Nanometer-scale roughness can determine adhesion, spreading, and motile

3 activity of cells and affect synthesis of specific proteins [33]. However, some data suggest that

4 cells are attached better to rough surfaces than to polished ones, whereas other data indicate that

5 changes in roughness are not accompanied by any cellular effects [34]. The data in Table 3 show

6 considerable differences between the values of roughness of the films with different

7 compositions. Roughness is determined from the arithmetic average of the roughness profile

$8 \quad(\mathrm{Ra})$ and root mean squared roughness $(\mathrm{Rq})$.

The values of surface roughness of the films prepared from PHA copolymers differed considerably depending on the monomer composition and proportions (Table 3). The $\mathrm{P}(3 \mathrm{HB} / 4 \mathrm{HB})(25.0 / 75.0$ mol.\%) copolymer showed the highest value of the $\mathrm{Ra}-568.2 \mathrm{~nm}$, which was almost 8 times higher than the corresponding parameter of $\mathrm{P}(3 \mathrm{HB})$ films $-71.8 \mathrm{~nm}$. The lowest value of surface roughness - $92.9 \mathrm{~nm}$ - was determined for the $\mathrm{P}(3 \mathrm{HB} / 4 \mathrm{HB})$ (70.7/29.3) bipolymers. The $\mathrm{P}(3 \mathrm{HB} / 4 \mathrm{HB})(25.0 / 75.0)$ bipolymer had the highest Rq: $681.1 \mathrm{~nm}$.

Our results are in good agreement with the data reported by other authors [35-36], suggesting that incorporation of $3 \mathrm{HV}$ monomer units into the $\mathrm{P}(3 \mathrm{HB})$ chain increases the film surface roughness. The surfaces of the films of polylactic acid (PLA) and $\mathrm{P}(3 \mathrm{HB} / 3 \mathrm{HHx})$ were smoother than the surface of the films based on the $\mathrm{P}(3 \mathrm{HB} / 4 \mathrm{HB} / 3 \mathrm{HHx})$ terpolymers [37]. However, some data suggest that the increase in the $4 \mathrm{HB}$ content of the copolymer and oxygen plasma treatment decreased surface roughness, making the film surface smoother $[11,38]$. Thus, results obtained in the present study show that copolymers differing in chemical composition and proportions of monomers can be used to prepare films with markedly dissimilar surface microstructure and properties. 
2 solutions of the copolymers. Table 3 presents some results of measuring mechanical properties 3 of films prepared from PHAs of various compositions.

All copolymer films showed considerably higher elastic properties, expressed as elongation at break, than $\mathrm{P}(3 \mathrm{HB})$ films, but lower mechanical strength, expressed as Young's modulus and tensile strength. Elongation at break of $\mathrm{P}(3 \mathrm{HB} / 4 \mathrm{HB})$ films consistently increased from 5.7 to $323.4 \%$ as $4 \mathrm{HB}$ content increased from 10.4 to $75.0 \mathrm{~mol} . \%$, while elongation at break of $\mathrm{P}(3 \mathrm{HB})$ films was no more than $2-3 \%$. At the same time, $\mathrm{P}(3 \mathrm{HB} / 4 \mathrm{HB})$ films showed some decrease in tensile strength and a dramatic decrease in Young's modulus, which dropped to between 242.9 and 975.7 MPa, relative to Young's modulus of $\mathrm{P}(3 \mathrm{HB})$ films - 1764.0 MPa. Analysis of the literature data, including reviews by Laycock, also suggested that elasticity of polymer films increased with an increase in $4 \mathrm{HB}$ content of the copolymers, but the data on mechanical properties of $\mathrm{P}(3 \mathrm{HB} / 4 \mathrm{HB})$ bipolymers reported by different authors varied widely [3, 39]. For instance, Ramachandran and Amirul investigated copolymers with $4 \mathrm{HB}$ content of no more than 20-40 mol.\% and reported their Young's modulus values of between 10 and $119 \mathrm{MPa}$, tensile strength of between 1 and $12 \mathrm{MPa}$, and elongation at break of between 1 and 300-400\% [13]. Comparable values of the three parameters of copolymers with the same 4HB content were reported by Huong et al. [30]. By contrast, Iqbal and Amirul reported lower values of mechanical properties for copolymers containing higher percentages of 4HB (47 and 65 mol.\%) [12]. These contradictions are most likely associated with different processes of preparing films; moreover, most of the authors do not provide geometric properties of their samples.

Films prepared from terpolymers containing $3 \mathrm{HB}, 4 \mathrm{HB}$, and $3 \mathrm{HV}$ also showed enhanced elasticity and an even greater decrease in mechanical strength (Table 3). The data reported in the literature for $\mathrm{P}(3 \mathrm{HB} / 3 \mathrm{HV} / 4 \mathrm{HB})$ terpolymers are very contradictory. In the copolymer with $4 \mathrm{HB}$ content of 84 mol.\% [14, 37], elongation at break reached 300\%, which was higher by an order of magnitude than in $\mathrm{P}(3 \mathrm{HB} / 3 \mathrm{HV})$. Young's modulus increased to $392 \mathrm{MPa}$ in the copolymer 
1 with 3 HV 23 mol.\% and 4HB 66 mol.\%, which was 13 times higher than Young's modulus of

$2 \mathrm{P}(3 \mathrm{HB} / 4 \mathrm{HB})$. The copolymer containing $3 \mathrm{HV} 34 \mathrm{~mol} \%$ and $4 \mathrm{HB} 55 \mathrm{~mol} \% \%$ showed an increase

3 in Young's modulus to $618 \mathrm{MPa}$.

4

For $\mathrm{P}(3 \mathrm{HB} / 3 \mathrm{HV} / 4 \mathrm{HB} / 3 \mathrm{HHx})$ quaterpolymers, which had a higher degree of crystallinity, elongation at break was somewhat lower than for bipolymers and terpolymers, but although it was no more than $100 \%$, it was significantly higher than elongation at break of $\mathrm{P}(3 \mathrm{HB})$. Mechanical strength parameters were lower for all quaterpolymer samples. Young's modulus dropped to 127.8-419.4 MPa and tensile strength to 7.3-11.7 MPa, and these values were two orders of magnitude lower than the values of the corresponding parameters of $\mathrm{P}(3 \mathrm{HB})$. We did not reveal any direct relationship between physical/mechanical properties of the quaterpolymers and proportions of monomers, including $4 \mathrm{HB}$, in them, but we did observe a dramatic increase in elongation at break and a decrease in Young's modulus compared to $\mathrm{P}(3 \mathrm{HB})$, suggesting higher ductility of the quaterpolymers.

\subsection{Biological properties of PHAs with different compositions}

Biological properties of bi-, ter-, and quaterpolymer films are illustrated by photographs showing fibroblasts stained with fluorescent dyes - markers of nuclear DNA (DAPI) and cell cytoplasm (phalloidin conjugated to FITC) (Fig. 3). Polystyrene of culture plates was used as control. DAPI and FITC staining didn't reveal any cytotoxic effect of P(3HB) and PHA bi-, ter-, and quaterpolymers. Morphology of physiologically active cells showed that the best results were obtained on the PHA films.

Thus, none of the PHA types investigated in this study showed cytotoxicity, i.e. the study proved their high biocompatibility and better performance as cell scaffolds compared to $\mathrm{P}(3 \mathrm{HB})$ and polystyrene.

\section{Conclusions}

In this study, we compared properties of PHA bi-, ter-, and quaterpolymers that contained different concentrations of $4 \mathrm{HB}$ monomer units. $4 \mathrm{HB}$ monomer units produced the strongest 
1 effect on the degree of crystallinity of PHAs, reducing this parameter to $30-40 \%$ compared to the

2 high-crystallinity $\mathrm{P}(3 \mathrm{HB})(67 \%)$. Synthesis of PHA ter- and quaterpolymers that, in addition to

$34 \mathrm{HB}$, contained $3 \mathrm{HV}$ and $3 \mathrm{HHx}$ monomer units increased the effect of $4 \mathrm{HB}$ on $\mathrm{C}_{\mathrm{x}}$. Copolymers

4 containing $4 \mathrm{HB}$ were more ductile than homogenous $\mathrm{P}(3 \mathrm{HB})$ : their values of elongation at break

5 were higher than that of $\mathrm{P}(3 \mathrm{HB})$. However, their mechanical strength was lower. All copolymers

6 containing 4HB were highly biocompatible and suitable for fabricating cell scaffolds for cellular

7 and tissue engineering.

\section{Acknowledgement}

The research was supported by the Russian Science Foundation (grant No. 17-15-01352)

\section{References}

[1] Biomaterials, artificial organs and tissue engineering, L.L. Hench, J.R. Jones (Eds.) CRC Press, BocaRaton, 2005.

[2] K. Sudesh, H. Abe, Y. Doi, Synthesis, structure and properties of polyhydroxyalkanoates: biological polyesters, Prog. Polym. Sci. 25 (2000) 1503-1555.

[3] B. Laycock, P. Halley, S. Pratt, A. Werker, P. Lant, The chemomechanical properties of microbial polyhydroxyalkanoates, Prog. Polym. Sci. 38 (2013) 536-583.

[4] T.G. Volova, E.I. Shishatskaya, A.J. Sinskey, Degradable Polymers: Production, Properties and Applications, Nova Science Publishers, New York, 2013.

[5] Y. Doi, A. Segawa, M. Kunioka, Biosynthesis and characterization of poly(3hydroxybutyrate-co-4-hydroxybutyrate) in Alcaligenes eutrophus, Int. J. Biol. Macromol. 12 (1990) 106-11.

[6] Y. Saito, Y. Doi, Microbial synthesis and properties of poly(3-hydroxybutyrate-co-4hydroxybutyrate) in Comamonas acidovorans, Int. J. Biol. Macromol. 16 (1994) 99-104.

[7] S. Vigneswari, S. Vijaya, M.I.A. Majid, K. Sudesh, C.S. Sipaut, M.N.M. Azizan, A.A. Amirul, Enhanced production of poly(3-hydroxybutyrate-co-4-hydroxybutyrate) copolymer 
1 with manipulated variables and their properties, J. Ind. Microbial. Biotechnol. 36 (2009) 5472556.

[8] D.H. Park, B.S. Kim, Production of poly(3-hydroxybutyrate) and poly(34 hydroxybutyrate-co-4-hydroxybutyrate) by Ralstonia eutropha from soybean oil, New $5 \quad$ Biotechnol. 28 (2011) 719-724.

[9] J.M.B.T. Cavalheiro, R.S. Raposo, M.C.M.D. de Almeida, M.T. Cesário, C. Sevrin, 7 C. Grandfils, M.M.R. da Fonseca, Effect of cultivation parameters on the production of poly(38 hydroxybutyrate-co-4-hydroxybutyrate) and poly(3-hydroxybutyrate-4-hydroxybutyrate-39 hydroxyvalerate) by Cupriavidus necator using waste glycerol, Bioresour. Technol. 111 (2012) 391-397.

[10] S. Chanprateep, Y. Kotakura, S. Visetkoop, H. Shimizu, S. Kulpreecha, S. Shioya, Characterization of new isolated Ralstonia eutropha strain A-04 and kinetic study of biodegradable copolyester poly(3-hydroxybutyrate-co-4-hydroxybutyrate) production, J. Ind. Microbiol. Biotechnol. 35 (2008) 1205-1215.

[11] S. Chanprateep, K. Buasri, A. Muangwong, P. Utiswannakul, Biosynthesis and biocompatibility of biodegradable poly(3-hydroxybutyrate-co-4-hydroxybutyrate), Polym. Degrad. Stab. 95 (2010) 2003-2012.

[12] N.Md. Iqbal, A.A. Amirul, Synthesis of P(3HB-co-4HB) copolymer with targetspecific 4HB molar fractions using combinations of carbon substrates, J. Chem. Technol. Biotechnol. 89 (2014) 407-418.

[13] H. Ramachandran, A.A. Amirul, Bioconversion of glycerine pitch into a novel yellow-pigmented $\mathrm{P}(3 \mathrm{HB}-\mathrm{co}-4 \mathrm{HB})$ copolymer: synergistic effect of ammonium acetate and polymer characteristics, Appl. Biochem. Biotechnol. 172 (2014) 891-909.

[14] S. Chanprateep, S. Kulpreecha, Production and characterization of biodegradable 25 terpolymer poly(3-hydroxybutyrate-co-3-hydroxyvalerate-co-4-hydroxybutyrate) by Alcaligenes 26 sp. A-04. J. Biosci. Bioeng. 101 (2006) 51-56. 
[15] M. Koller, P. Hesse, R. Bona, C. Kutschera, A. Atlić, G. Braunegg, Biosynthesis of

2 high quality polyhydroxyalkanoate co-and terpolyesters for potential medical application by the

3 archaeon Haloferax mediterranei, Macromol. Symposia 253 (2007) 33-39.

4

[16] T.M.F. Azira, A.A. Nursolehah, Y. Norhayati, M.I.A. Majid, A.A. Amirul, Biosynthesis of Poly(3-hydroxybutyrate-co-3-hydroxyvalerate-co4-hydroxybutyrate) terpolymer by Cupriavidus sp. USMAA2-4 through two-step cultivation process, World J. Microbiol. Biotechnol. 27 (2011) 2287-2295.

[17] H. Ramachandran, N.Md. Iqbal, C.S. Sipaut, A.A.-A. Abdullah, Biosynthesis and Characterization of poly (3-hydroxybutyrate-co-3-hydroxyvalerate-co-4-hydroxybutyrate) terpolymer with various monomer compositions by Cupriavidus Sp. USMAA2-4, Appl. Biochem. Biotechnol. 164 (2011) 867-877.

[18] T. Volova, N. Zhila, E. Kiselev, E. Shishatskaya, A study of synthesis and properties of poly-3-hydroxybutyrate/diethylene glycol copolymers, Biotechnol. Prog. 32 (2016) 10171028.

[19] O. Vinogradova, T. Volova, Biosynthesis and properties of PHA containing monomers 3-hydroxy-4-methylvalerate, J. Siberian Federal University. Biology 9 (2016) 1145152.

[20] T.G. Volova, E.G. Kiselev, E.I. Shishatskaya, N.O. Zhila, A.N. Boyandin, D.A. Syrvacheva, O.N. Vinogradova, G.S. Kalacheva, A.D. Vasiliev, I.V. Peterson, Cell growth and accumulation of polyhydroxyalkanoates from $\mathrm{CO}_{2}$ and $\mathrm{H}_{2}$ of a hydrogen-oxidizing bacterium, Cupriavidus eutrophus B-10646, Bioresour. Technol. 146 (2013) 215-222.

[21] T. Volova, E. Kiselev, O. Vinogradova, E. Nikolaeva, A. Chistyakov, A. Sukovatiy, E. Shishatskaya, A glucose-utilizing strain, Cupriavidus euthrophus B-10646: growth kinetics, characterization and synthesis of multicomponent PHAs, PLoS One 9 (2014) 1-15. 
[22] T.G. Volova, O.N. Vinogradova, N.O. Zhila, I.V. Peterson, E.G. Kiselev, A.D.

2 Vasiliev, A.G. Sukovatiy, E.I. Shishatskaya, Properties of a novel quaterpolymer $3 \mathrm{P}(3 \mathrm{HB} / 4 \mathrm{HB} / 3 \mathrm{HV} / 3 \mathrm{HHx})$. Polymer 101 (2016) 67-74.

4

[23] T.G. Volova, O.N. Vinogradova, N.O. Zhila, E.G. Kiselev, I.V. Peterson, A.D. Vasil'ev, A.G. Sukovatyi, E.I. Shishatskaya, Physicochemical properties of multicomponent polyhydroxyalkanoates: novel aspects, Polymer Science, Series A 59 (2017) 76-85.

[24] H. Mitomo, W.-C. Hsieh, K. Nishiwaki, K. Kasuya, Y. Doi, Poly(3hydroxybutyrate-co-4-hydroxybutyrate) produced by Comamonas acidovorans, Polymer 42 (2001) 3455-3461.

[25] M. Scandola, G. Ceccorulli, M. Pizzoli, M. Gazzano, Study of the crystal phase and crystallization rate of bacterial poly( $\beta$-hydroxybutyrate-co- $\beta$-hydroxyvalerate), Macromol. 25 (1992) 1405-1410.

[26] T. Iwata, Y. Doi, Crystals structure and biodgradation of aliphatic polyesters crystals, Macromol. 30 (1997) 5290-5296.

[27] T. Iwata, Y. Doi, S. Nakayama, H. Sasatsuki, S. Teramachi, Structure and enzymatic degradation of poly(3-hydroxybutyrate) copolymer single crystals with an extracellular PHB depolymerase from Alcaligenes faecalis T1, Int. J. Biol. Macromol. 25 (1999) 169-176.

[28] D. Byrom, Polyhydroxyalkanoates, in: D.P. Mobley (Ed.), Plastic from Microbes: Microbial Synthesis of Polymers and Polymer Precursors, Hanser, Munich, 1994, pp. 5-33.

[29] S. Chanprateep, Current trends in biodegradable polyhydroxyalkanoates, J. Biosci. Bioeng. 110 (2010) 621-632.

[30] K.H. Huong, S. Kannusamy, S.Y.H. Lim, A.A. Amirul, Biosynthetic enhancement of single-stage poly(3-hydroxybutyrate-co-4-hydroxybutyrate) production by manipulating the substrate mixtures, J. Ind. Microbiol. Biotechnol. 42 (2015) 1291-1297. 
[31] L.A. Madden, A.J. Anderson, J. Asrar, P. Garrett, Production and characterization of

2 poly(3-hydroxtybutyrate-co-3-hydroxyvalerate-co-4-hydroxybutyrate) synthesized by Ralstonia

3 eutropha in fed-batch cultures, Polymer 41 (2000) 3499-3505.

4

[32] W. Ou, H. Qiu, Z. Chen, K. Xu, Biodegradable block poly(ester-urethane)s based on poly(3-hydroxybutyrat-co-4-hydroxybutyrate) copolymers, Biomaterials 32 (2011) 3178-3188.

[33] S.P. Xavier, P.S.P. Carvalho, M.M. Beloti, A.L. Rosa, Response of rat bone marrow cells to commercially pure titanium submitted to different surface treatments, J. Dent. 31 (2003) $173-80$.

[34] A.P. Boskhomdzhiev, Izucheniye biodestruktsii i biosovmestimosti polimernykh system na osnove polioxialkanoatov (A study of biodegradation and biocompatibility of polyhydroxyalkanoates-based polymer systems), Summary of $\mathrm{PhD}$ thesis, Moscow, A.N. Bakh Institute of Biochemistry RAS, 2010.

[35] A. Bera, S. Dubey, K. Bhayani, D. Mondal, S. Mishra, P.K. Ghosh, Microbial synthesis of polyhydroxyalkanoate using seaweed-derived crude levulinic acid as co-nutrient, Int. J. Biol. Macromol. 72 (2015) 487-494.

[36] L.H. Poley, A.P.L. Siqueira, M.G. da Silva, R. Sanchez, R. Prioli, A.M. Mansanares, H. Vargas, Photothermal methods and atomic force microscopy images applied to the study of poly(3-hydroxybutyrate) and poly(3-hydroxybutyrate-co-3-hydroxyvalerate) dense membranes, J. Appl. Polym. Sci. 97 (2005) 1491-1497.

[37] X. Wei, Y.J. Hu, W.P. Xie, R.L. Lin, G.Q. Chen, Influence of poly(3hydroxybutyrate-co-4-hydroxybutyrate-co-3-hydroxyhexanoate) on growth and osteogenic differentiation of human bone marrow-derived mesenchymal stem cells, J. Biomed. Mater. Res. A. 90 (2009) 894-905.

[38] J. Zhang, K. Kasuya, A. Takemura, A. Isogai, T. Iwata, Properties and enzymatic degradation of poly(acrylic acid) grafted polyhydroxyalkanoate films by plasma-initiated polymerization, Polym. Degrad. Stab. 98 (2013) 1458-1464. 
[39] B. Laycock, M.V. Arcos-Hernandez, A. Langford, J. Buchanan, P.J. Halley, A.

2 Werker, P.A. Lant, S. Pratt, Thermal properties and crystallization behavior of fractionated 3 blocky and random polyhydroxyalkanoate copolymers from mixed microbial cultures, J. Appl.

$4 \quad$ Polym. Sci. 11 (2014) 791-808

5

6

7

8

9

10

11

12

13

14

15

16

17

18

19

20

21

22

23

24

25

26

27

28

29

30

31

32

33

34

35

36

37

38

39

40

41

42

43

44

45 
2 different proportions of monomers

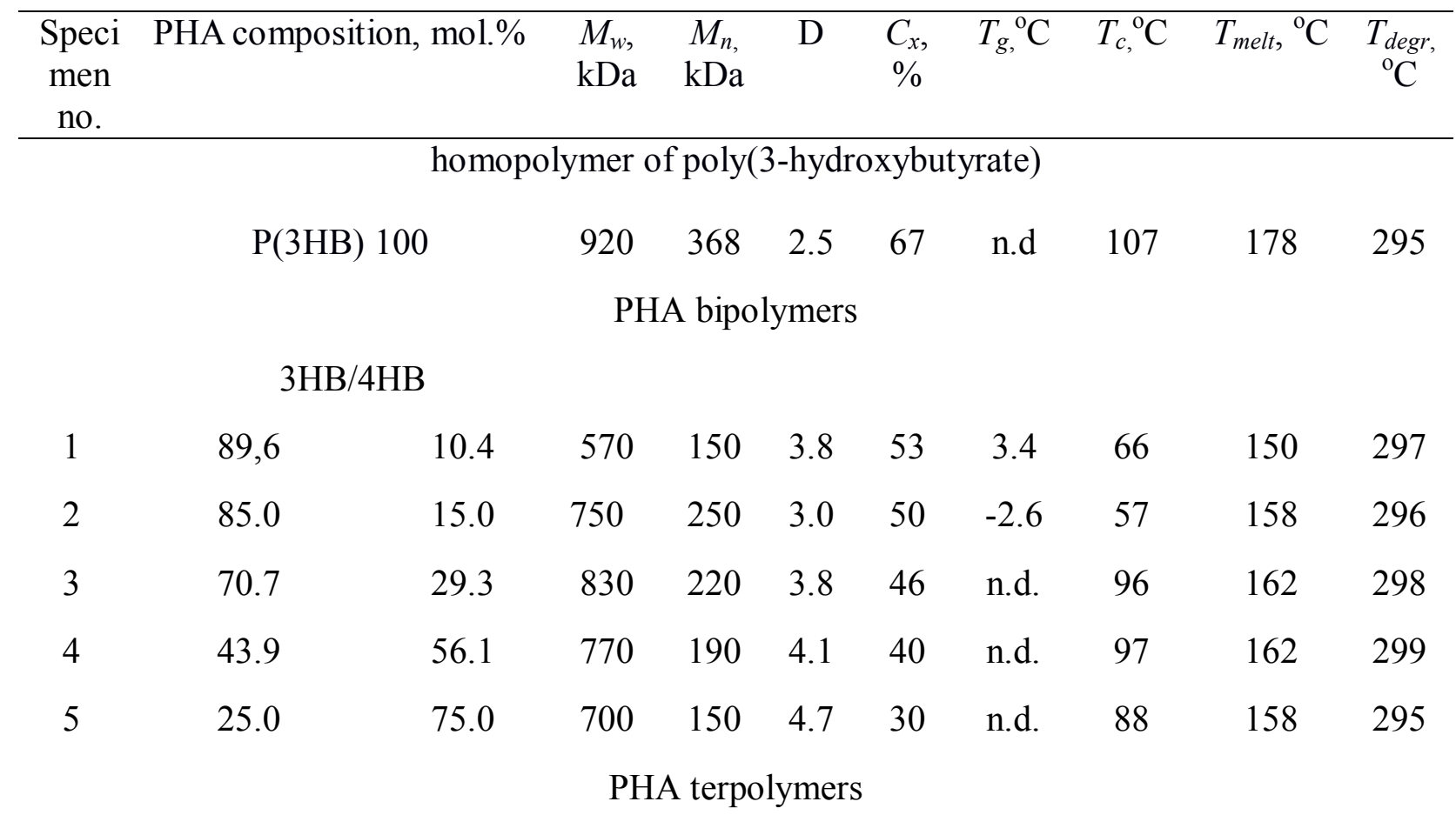

$3 \mathrm{HB} / 3 \mathrm{HV} / 4 \mathrm{HB}$

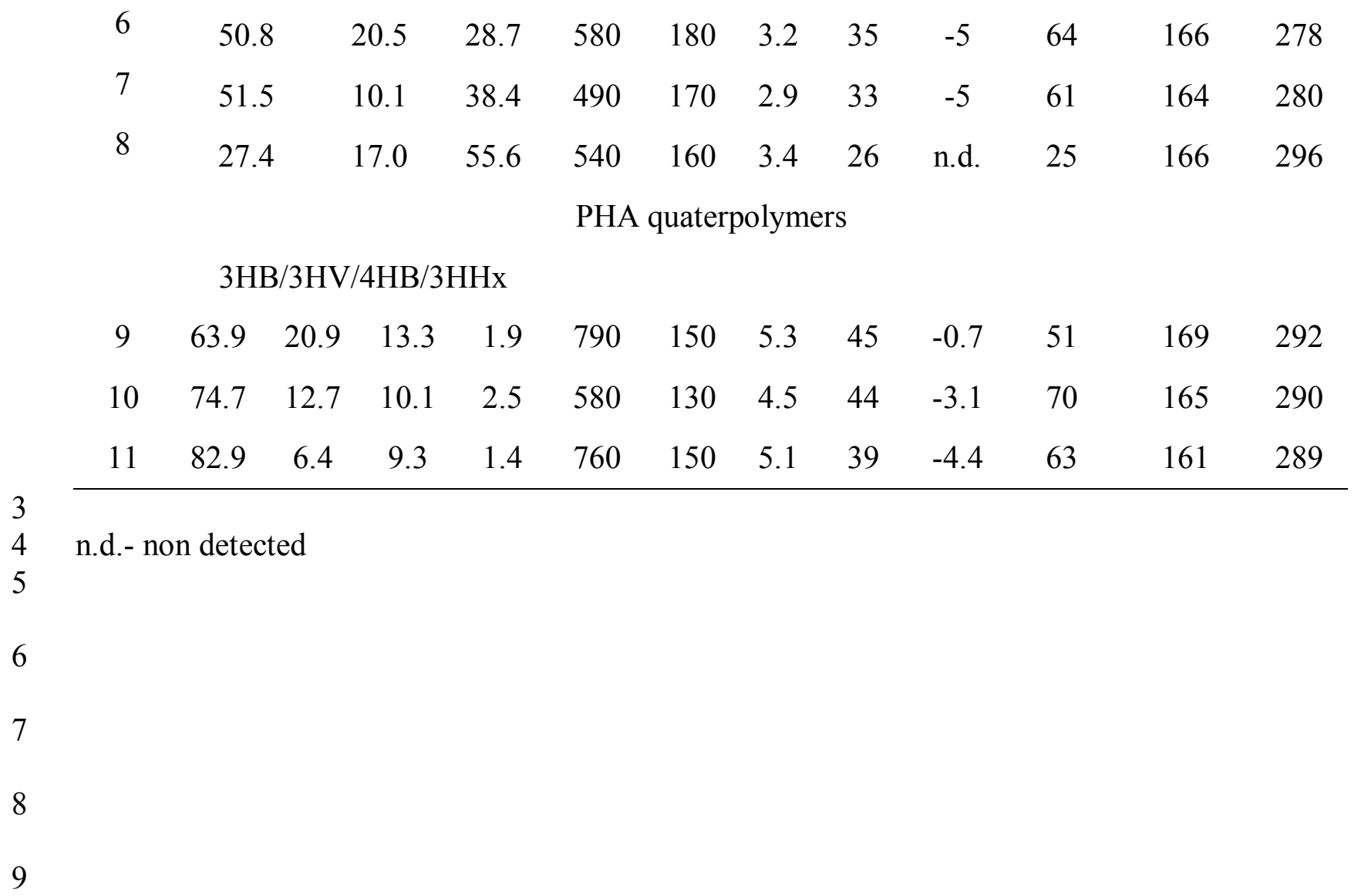


$2 \mathrm{P}(3 \mathrm{HB} / 3 \mathrm{HV} / 4 \mathrm{HB})$, and $\mathrm{P}(3 \mathrm{HB} / 3 \mathrm{HV} / 4 \mathrm{HB} / 3 \mathrm{HHx})$ copolymers with different monomer contents

3 (numbers according to Table 1)

\begin{tabular}{|c|c|c|c|c|}
\hline Specimen no. & $\begin{array}{l}\text { Contact angle } \\
\text { for water, }{ }^{\circ}\end{array}$ & $\begin{array}{l}\text { Contact angle for } \\
\text { diiodomethane, }\end{array}$ & $\begin{array}{c}\text { Surface free } \\
\text { energy, erg } / \mathrm{cm}^{2}\end{array}$ & $\begin{array}{c}\text { Polar component } \\
\text { of surface free } \\
\text { energy, erg } / \mathrm{cm}^{2}\end{array}$ \\
\hline $\mathrm{P}(3 \mathrm{HB})$ & $97.4 \pm 2.6$ & $58.5 \pm 1.4$ & $30.4 \pm 1.0$ & $1.2 \pm 0.2$ \\
\hline 1 & $89.8 \pm 1.6$ & $48.9 \pm 1.1$ & $36.8 \pm 1.1$ & $1.9 \pm 0.1$ \\
\hline 2 & $88.0 \pm 2.4$ & $49.6 \pm 0.7$ & $36.9 \pm 0.2$ & $2.4 \pm 0.1$ \\
\hline 3 & $78.6 \pm 1.2$ & $42.0 \pm 1.1$ & $44.5 \pm 1.1$ & $4.2 \pm 0.1$ \\
\hline 4 & $92.5 \pm 1.3$ & $47.8 \pm 1.4$ & $36.7 \pm 1.1$ & $1.2 \pm 0.1$ \\
\hline 5 & $90.6 \pm 1.3$ & $45.5 \pm 1.1$ & $38.4 \pm 1.1$ & $1.5 \pm 0.2$ \\
\hline 6 & $83.7 \pm 5.2$ & $54.5 \pm 1.1$ & $36.0 \pm 0.5$ & $4.2 \pm 0.2$ \\
\hline 7 & $96.6 \pm 1.1$ & $80.5 \pm 2.3$ & $20.7 \pm 0.4$ & $3.4 \pm 0.1$ \\
\hline 8 & $81.7 \pm 0.8$ & $48.6 \pm 2.1$ & $39.3 \pm 0.5$ & $4.2 \pm 0.1$ \\
\hline 9 & $88.9 \pm 3.7$ & $45.4 \pm 1.9$ & $38.7 \pm 1.2$ & $1.9 \pm 0.2$ \\
\hline 10 & $89.0 \pm 1.8$ & $40.2 \pm 1.2$ & $40.9 \pm 1.1$ & $1.4 \pm 0.0$ \\
\hline 11 & $99.7 \pm 2.4$ & $50.2 \pm 1.0$ & $34.5 \pm 1.2$ & $0.3 \pm 0.0$ \\
\hline
\end{tabular}

4

5

6

7

8

9

10 
2 compositions (numbers according to Table 1)

\begin{tabular}{|c|c|c|c|c|c|}
\hline Specimen no. & $\begin{array}{l}\text { Tensile } \\
\text { strength, } \\
\mathrm{MPa}\end{array}$ & $\begin{array}{l}\text { Young's } \\
\text { modulus, } \\
\mathrm{MPa}\end{array}$ & $\begin{array}{l}\text { Elongation } \\
\text { at break, \% }\end{array}$ & $\begin{array}{c}\mathrm{Ra}- \\
\text { arithmetic } \\
\text { average of } \\
\text { the } \\
\text { roughness } \\
\text { profile, } \mathrm{nm}\end{array}$ & $\begin{array}{l}\mathrm{Rq}-\text { root } \\
\text { mean } \\
\text { squared } \\
\text { roughness, } \\
\text { nm }\end{array}$ \\
\hline $\mathrm{P}(3 \mathrm{HB})$ & 20.9 & 1764.0 & 3.2 & 71.8 & 80.3 \\
\hline 1 & 14.8 & 975.7 & 5.7 & 92.9 & 113.1 \\
\hline 3 & 7.8 & 242.9 & 30.7 & 177.6 & 248.1 \\
\hline 5 & 15.4 & 424.8 & 323.4 & 568.2 & 681.1 \\
\hline 7 & 5.3 & 130.5 & 47.6 & 126.5 & 170.7 \\
\hline 8 & 8.8 & 34.3 & 365.4 & 184.5 & 221.8 \\
\hline 9 & 7.3 & 127.8 & 93.7 & 132.5 & 172.9 \\
\hline 11 & 11.7 & 419.4 & 49.0 & 283.8 & 348.5 \\
\hline
\end{tabular}

3

4

5

6

7

8

9 
Figure 1. ${ }^{1} \mathrm{H}$ NMR spectra of copolymer samples: $\mathrm{a}-\mathrm{P}(3 \mathrm{HB}) ; \mathrm{b}-\mathrm{P}(3 \mathrm{HB} / 56.1$ mol. \%3 4HB); c - P(3HB/20.5 mol.\%-3HV/28.7 mol.\%-4HB); d - P(3HB/20.9 mol.\%-3HV/13.3 mol.\%$4 \quad 4 \mathrm{HB} / 1.9 \mathrm{~mol} . \%-3 \mathrm{HHx})$.

Figure 2. SEM images of the films prepared from PHAs with different compositions: A -

$6 \mathrm{P}(3 \mathrm{HB} / 29.3 \mathrm{~mol} \%-4 \mathrm{HB}), \mathrm{B}-\mathrm{P}(3 \mathrm{HB} / 75.0 \mathrm{~mol} \%-4 \mathrm{HB}), \mathrm{C}-\mathrm{P}(3 \mathrm{HB} / 10.1 \mathrm{~mol} . \%-3 \mathrm{HV} / 38.4$

7 mol.\%-4HB), D - P(3HB/17.0 mol.\%-3HV/55.6 mol.\%-4HB), E - P(3HB/20.9 mol.\%-3HV/13.3

8 mol.\%-4HB/1.9 mol.\%-3HHx), F - P(3HB).

Figure 3. FITC and DAPI fluorescent staining of NIH 3 T3 mouse fibroblast cells 10 cultivated on films of PHAs of different composition at Day 3 of cultivation. 